\title{
Safety profile of atorvastatin in post myocardial infarction and post stroke patients
}

\author{
M ohamed Salim Valiyakathody ${ }^{1 *}$, Soopy Kayanaduth², Roopashree Gopinath ${ }^{3}$, M uneer R E ${ }^{4}$
}

\author{
${ }^{1}$ Assistant Professor, Department of Pharmacology, Government Medical College, Kozhikode, Kerala, INDIA. \\ ${ }^{2}$ Asso ciate Professor, Department of M edicine, Government Medical College, Ko zhiko de, Kerala, INDIA \\ 3Kaplan University, Davenport, lowa, USA, \\ ${ }^{4}$ Consultant Physician Co Operative Ho spital Vadakara Kerala, INDIA. \\ Email: ergot501@ gmail.com
}

\begin{abstract}
Background: The side effects of high dose atorvastatin treatment in post myocardial infarction and post stroke patients have not been studied in detail. The present work aim to study whether the toxicity profile of atorvastatin in Indian population is same as that of western countries. There are reports that atorvastatin decreases C-reactive protein levels in blood. This study further target to find whether the reduction in C-protein levels are dose dependent about which no conclusive data is available. Methodology: This observational prospective study was conducted in the subjects admitted with acute myocardial infarction or cerebrovascular accident in the form of infarct and started on atorvastatin as a part of treatment. 100 subjects in the age group 35-75 years were chosen and they were categorized into two different groups. The $1^{\text {st }}$ group had subjects who were taking $10 \mathrm{mg}$ and the $2^{\text {nd }}, 40 \mathrm{mg}$ of atorvastatin. The comparison of serum creatinine, serum uric acid, serum glutamate pyruvate transaminase (SGPT) and creatinine phosphokinase (CPK) were measured. They were followed up twice (at 6 weeks and 12 weeks) during the study period of 3 months and adverse effects were carefully monitored by clinical parameters and laboratory investigations. Results: After the 12 weeks study period, it was found that atorvastatin is well tolerated in low and high doses with minimal side effects and no dose response relationship was found in overall incidence of adverse effects. Besides, the reduction in C-reactive protein values with atorvastatin therapy following coronary and cerebrovascular events was not dose dependent. Conclusion: There is no significant difference in adverse outcome as far as low dose or high dose of atorvastatin usage is concerned in post coronary or cerebrovascular event therapy. And in addition the drug appeared to be safe and did not produce any major side effects in the study population during this trial.

Key Words: Atorvastatin, myocardial infarction, stroke, creatinine, SGPT and CPK.
\end{abstract}

*Address for Correspondence:

Dr. Mohamed Salim Valiyakathody Assistant Professor, Department of Pharmacology, Government Medical College, Kozhikode, Kerala. Received Date: 03/08/2018 Revised Date: 10/09/2018 Accepted Date: 25/10/2018

DOI: https://doi.org/10.26611/1010911

\begin{tabular}{|c|l|}
\hline \multicolumn{2}{|c|}{ Access this article online } \\
\hline Quick Response Code: & Website: \\
\hline & www.medpulse.in \\
\hline
\end{tabular}

\section{INTRODUCTION}

Human beings are doggedly confronting life-threatening morbidities such as cardiovascular and cerebrovascular disorders. Cardiovascular diseases annually account for $\sim 17$ million deaths globally ${ }^{1}$. Whereas, stroke is the third leading cause of death worldwide after Ischemic Heart Disease (IHD) and Cancer ${ }^{2}$. The risk of cardiovascular mortality and morbidity are further increases among patients those who survived a stroke. India has a disproportionately higher burden of coronary artery disease than most developing countries. Atherosclerosis is the main factor for the pathogenesis of myocardial and cerebral infarctions. Nevertheless, high levels of plasma low density lipoproteins (LDL) and triglycerides (TG) along with decreased levels of high-density lipoproteins (HDL) are often the major root cause of atherosclerosis and ultimately myocardial and cerebral infarctions ${ }^{1,3}$. Since hyperlipidaemia is the most important risk factor for coronary artery disease, statins have become the first line therapy for reducing the risk of cardiovascular disease mortality. For instance, hyperlipidaemia is also important as a risk factor for cerebrovascular diseases, the 
reduction in blood lipid level is an essential part of the treatment of cerebrovascular incidents. Atorvastatin is a widely prescribed drug to treat dyslipidaemia. The effectiveness of atorvastatin in lowering the cholesterol level is dose related and has been used in various doses ranging from $5 \mathrm{mg}$ to $80 \mathrm{mg}^{4}$. Statins are structural analogues of HMG CoA and competitively inhibit HMG CoA reductase, which catalyses the rate limiting step in cholesterol biosynthesis. Thus by reducing intracellular levels of cholesterol, atorvastatin up-regulate the expression of LDL receptors in liver cells and it leads to increased clearance of LDL from the blood stream ${ }^{5}$. In addition to improving lipid profile, statin have several beneficial biological, pleiotropic effects that contribute to their overall clinical benefit. These include reducing platelet aggregation and thrombus formation, improving fibrinolytic profile and lowering the inflammation and Creactive protein. In patients with coronary artery disease and hyperlipidaemia, statins improve endothelial function, decrease plasma concentration of tumour necrosis factor alpha (TNF- $\alpha$ ) and thereby reduces the morbidity and mortality ${ }^{6-8}$. There is increasing concern about the reports of increased risk of toxicities associated with statin therapy. The concern regarding the safety of HMG-CoA reductase inhibitors peaked after the voluntary worldwide withdrawal of Cerivastatin in August 2001, due to increased incidence of fatal rhabdomyolysis associated with its intake. The other serious adverse reactions reported include myositis, myopathy, polyneuropathy, cancer, liver and kidney toxicities, diabetes mellitus and haemorrhagic stroke. The minor adverse effects of statin therapy include abdominal cramps, diarrhoea or constipation, flatulence, dyspepsia, muscle pain, dizziness, headache, pharyngitis, flu syndrome, nausea and vomiting, sleep disturbances, fatigue, change in body temperature and blood sugar and dry skin 9 . The side effects of high dose atorvastatin treatment in post myocardial infarction and post stroke patients have not been studied in detail. The present work also aim to study whether the toxicity profile of atorvastatin in Indian population is same as that of western countries. There are reports that atorvastatin decreases C-reactive protein levels in blood. This study further target to find whether the reduction in C-protein levels are dose dependent about which no conclusive data is available.

\section{MATERIALS AND METHODS}

This observational prospective study was conducted in the casualty department and inpatient wards of general medicine department, Government medical college, Kozhikode. Subjects admitted with acute myocardial infarction or cerebrovascular accident in the form of infarct and started on atorvastatin as a part of current treatment were looked for. 100 subjects in the age group 35-75 years who fit the inclusion criteria were chosen. An informed written consent was obtained from all participants. Depending on their intake dosage of atorvastatin, they were categorized into two different groups. The first group had subjects who were taking 10 $\mathrm{mg}$ and the second, $40 \mathrm{mg}$ of atorvastatin. The clinical parameters were assessed (serum creatinine, serum uric acid, serum glutamate pyruvate transaminase [SGPT] and creatinine phosphokinase [CPK]) and baseline investigations carried out in both groups. They were followed up twice (at 6 weeks and 12 weeks) during the study period of 3 months and adverse effects were carefully monitored by clinical parameters and laboratory investigations.

Sample size: Sample population consisted of 100 subjects were divided into two equal limbs on the basis of their drug dosage.

Inclusion Criteria: Subjects between 35-70 years admitted with acute myocardial infarction or cerebrovascular accident (infarct) and started on atorvastatin $10 \mathrm{mg}$ or $40 \mathrm{mg}$ as part of current treatment.

Exclusion Criteria: The following patients were excluded from the study - uncontrolled diabetes mellitus, uncontrolled hypertension, hypothyroidism, chronic alcoholic history, gastrointestinal diseases affecting absorption, any type of malignancy, past history of coronary revascularization procedures, significant valvular heart disease, serum creatinine $>2 \mathrm{mg} / \mathrm{dL}$, cardiac failure with EF (ejection fraction) $<30 \%$, abnormal liver enzyme values ( $>$ two times the upper limit for normal), unexplained creatinine kinase levels $>6$ times the normal, concomitant use of azoles, erythromycin, clarithromycin, cyclosporine, fibrates and niacin.

Statistical Analysis: Data regarding comparison of safety profile of atorvastatin in low and high dosage in post myocardial infarction and post stroke patients were collected, coded and entered in Microsoft Excel sheet which was rechecked and analysed using SPSS 16 statistical software. Description of the study subjects was done using Frequencies for qualitative variables and Mean and Standard Deviation for quantitative variables. Statistical testing of association of side effects in both groups was done using Pearson Chi square test and independent sample ' $t$ ' tests. Statistical comparison was done using appropriate statistical tests and level of significance was taken as $p$ value of 0.05 .

\section{RESULTS}

A total of 100 patients who met the inclusion criteria were categorized into two groups based on their dosage intake of Atorvastatin. Those who took $10 \mathrm{mg}$ dosage 
were added to the first group and those on $40 \mathrm{mg}$ dosage added to the second group. They were monitored for a period of 3 months. By the end of trial period, there were 5 dropouts from $10 \mathrm{mg}$ group and 4 (including a death) in $40 \mathrm{mg}$ group. Dropout rate was $9 \%$, whereas response rate was $91 \%$. The age, sex and other baseline parameters were similar in both groups. Majority of participants in both groups were in 60-70 years age. In group I, 24 $(53.3 \%)$ of the participants were male and $21(46.7 \%)$ were females. Whereas in group II, 27 (58.7\%) were males and $19(41.3 \%)$ were females. Thus, both the study groups were comparable in age $(p-$ value $=0.77)$ and sex $(p$-value $=0.81)$ distribution (Figure 1 and 2$)$.

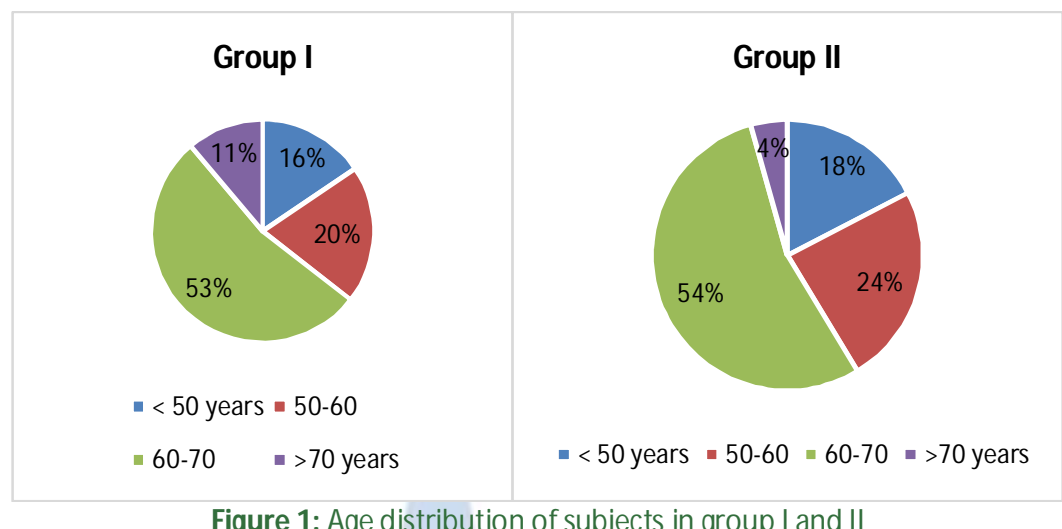

Figure 1: Age distribution of subjects in group I and II

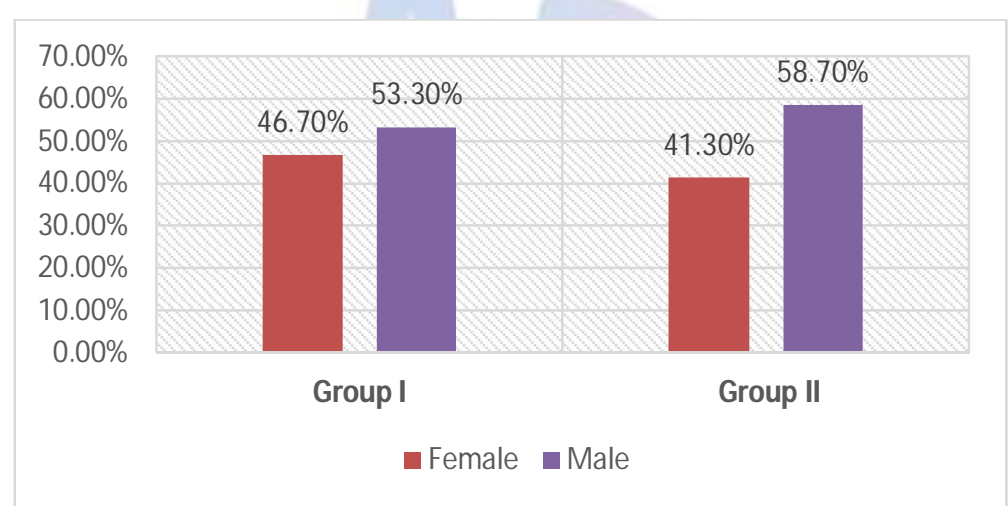

Figure 2: Gender wise distribution of subjects

In group I, there were 30 subjects having myocardial infarction (MI) and 15 having stroke, whereas in group II, these numbers were 30 and 16 respectively ( $p$-value = 0.35) (table 1).

Table 1: Distribution of M I and Stroke in Group I and II

\begin{tabular}{ccc}
\hline Disease & Group I $(\mathbf{n}=\mathbf{4 5})$ & Group II $(\mathbf{n}=46)$ \\
\hline MI & $30(66.7 \%)$ & $30(65.2 \%)$ \\
Stroke & $15(33.3 \%)$ & $16(34.8 \%)$ \\
\hline
\end{tabular}

The $\mathrm{C}$ - reactive protein (CRP) values of both the study groups at base line, 6 weeks and 12 weeks are shown in table 2. The decrease in CRP at 6 weeks and 12 weeks are comparable ( $p$ value -0.28 ) in both groups.

Table 2: Comparison of CRP values

\begin{tabular}{cccc}
\hline Variable & $\begin{array}{c}\text { Group I } \\
\text { (Mean } \pm \text { SD) }\end{array}$ & $\begin{array}{c}\text { Group II } \\
\text { (Mean } \pm \text { SD) }\end{array}$ & p- Value \\
\hline CRP at base & $5.3 \pm 10.2$ & $4.3 \pm 9.6$ & 0.63 \\
CRP at 6 weeks & $3.6 \pm 5.1$ & $2.5 \pm 3.1$ & 0.21 \\
CRP at 12 weeks & $1.8 \pm 1.9$ & $2.9 \pm 6.8$ & 0.28 \\
\hline
\end{tabular}

The comparison of serum creatinine, serum uric acid, serum glutamate pyruvate transaminase (SGPT) and creatinine phosphokinase (CPK) are shown in table 3, 4, 5 and 6 respectively.

Table 3: Comparison of serum creatinine(values are expressed in

\begin{tabular}{cccc}
\multicolumn{4}{c}{$\mathrm{mg} / \mathrm{dL})$} \\
Variable & $\begin{array}{c}\text { Group I } \\
(\text { Mean } \pm \text { SD })\end{array}$ & $\begin{array}{c}\text { Group II } \\
(\text { Mean } \pm \text { SD })\end{array}$ & p-Value \\
\hline Creatinine at base & $1.04 \pm 0.18$ & $1.03 \pm 0.22$ & 0.9 \\
Creatinine at 6 weeks & $1.04 \pm 0.22$ & $1.03 \pm 0.19$ & 0.9 \\
Creatinine at 12 weeks & $1.08 \pm 0.21$ & $1.04 \pm 0.21$ & 0.09 \\
\hline
\end{tabular}

Table 4: Comparison of serum uric acid (values are expressed in $\mathrm{mg} / \mathrm{dL}$ )

\begin{tabular}{cccc} 
Variable & $\begin{array}{c}\text { Group I } \\
\text { (Mean } \pm \text { SD) }\end{array}$ & $\begin{array}{c}\text { Group II } \\
\text { (Mean } \pm \text { SD) }\end{array}$ & p-Value \\
\hline Uric acid at base & $4.8 \pm 1.5$ & $4.7 \pm 1.5$ & 0.5 \\
Uric acid at 6 weeks & $4.7 \pm 1.3$ & $4.6 \pm 1.4$ & 0.6 \\
Uric acid at 12 weeks & $4.8 \pm 1.3$ & $4.7 \pm 1.4$ & 0.7 \\
\hline
\end{tabular}


Table 5: Comparison of SGPT level (values are expressed in U/L)

\begin{tabular}{|c|c|c|c|}
\hline Variable & $\begin{array}{c}\text { Group I } \\
\text { (Mean } \pm \text { SD) }\end{array}$ & $\begin{array}{c}\text { Group II } \\
(\text { Mean } \pm \text { SD) }\end{array}$ & p-Value \\
\hline SGPT at base & $34.1 \pm 14.2$ & $38.2 \pm 12.2$ & 0.9 \\
\hline SGPT at 6 weeks & $37.6 \pm 10.5$ & $42.0 \pm 9.4$ & 0.7 \\
\hline SGPT at 12 weeks & $39.1 \pm 11.0$ & $43.5 \pm 9.2$ & 0.7 \\
\hline \multicolumn{4}{|c|}{ Table 6: Comparison of CPK level (values are expressed in U/L) } \\
\hline Variable & $\begin{array}{c}\text { Group I } \\
\text { (Mean } \pm \text { SD) }\end{array}$ & $\begin{array}{c}\text { Group II } \\
\text { (Mean } \pm \text { SD) }\end{array}$ & $p$-Value \\
\hline CPK at base & $150.0 \pm 78.5$ & $130.9 \pm 55.2$ & 0.18 \\
\hline CPK at 6 weeks & $145.3 \pm 52.9$ & $142.5 \pm 53.3$ & 0.8 \\
\hline CPK at 12 weeks & $152.2 \pm 53.3$ & $143.0 \pm 58.2$ & 0.4 \\
\hline
\end{tabular}

One subject in each group has myalgia (without CPK elevation). One subject in group I complained of mild polyarthralgia and one subject in group II had insomnia. The percentage of subjects reporting adverse effects were $4.44 \%$ in $10 \mathrm{mg}$ group and $4.34 \%$ in $40 \mathrm{mg}$ group. There is no significant difference in adverse effects in both 10 $\mathrm{mg}$ and $40 \mathrm{mg}$ atorvastatin groups ( $p$ - value - 0.57) (table 7).

\begin{tabular}{ccc}
\multicolumn{4}{c}{ Table 7: Adverse effects in Group I and II } \\
\hline Adverse effect & Group I & Group II \\
\hline M yalgia & $1(2 \%)$ & $1(2.1 \%)$ \\
Polyarthralgia & $1(2 \%)$ & $0(0 \%)$ \\
Insomnia & $0(0 \%)$ & $1(2.1 \%)$ \\
\hline
\end{tabular}

\section{DISCUSSION}

The present study was a hospital based one carried out to compare the safety profile of atorvastatin in low $(10 \mathrm{mg})$ and high $(40 \mathrm{mg})$ doses in post myocardial infarction and post stroke patients. The baseline characteristics were similar in both groups. The drug was well tolerated in both the doses. It is well known that atorvastatin decrease the $\mathrm{C}$ - reactive protein values in myocardial infarction and other thromboembolic events due to its antiinflammatory effect. In the current study, the decrease in CRP from the baseline measured at 6 and 12 weeks were comparable in both the study groups. Changes in serum creatine and uric acid from the baseline showed no statistical significance in both the study groups. Hepatic function is also known to be affected by statin use ${ }^{10}$. This is measured by asymptomatic elevation of liver marker enzymes. In the present study, no subjects had elevated alanine amino transferase (ALT) or SGPT >3 times upper limit for normal. Moderate asymptomatic hepatic transaminase elevations ( $<3$ times upper limit of normal) are common among patients taking statins, but serious liver damage is extremely rare ${ }^{11}$. Whereas nearly $50 \%$ of dyslipidaemia patients have coexisting non-alcoholic fatty liver diseases (NAFLD), a condition well known for fluctuating transaminase levels ${ }^{12,13}$. But, related to hepatic function, there were no adverse effects reported in this study by the use of both the doses of atorvastatin. One of the most common complaints related to satin use is its effect on muscular function, ranging from myalgia to myositis. Myopathy is the general term for all potential muscle problems such as muscle pain or weakness and can occur with or without elevated CPK. Statin related myopathy is usually symmetrical, involves large proximal muscle groups and resolves within two months of discontinuation of the medication. It occurs in $5 \%$ of the statin treated patients in clinical trials and $10 \%$ patients in clinical practice. But severe muscle toxicity from statin therapy is rare. The risk of myopathy is not related to the low density lipoprotein (LDL) lowering efficacy, but the dose or blood concentration of $\operatorname{statin}^{14}$. In general elevation of creatinine phosphokinase (CPK) of $>10$ times upper limit for normal is regarded as significant elevations justifying the discontinuation of statin treatment. However, there were no such cases observed in our study. Furthermore, the elevation of CPK from the baseline were comparable in both the groups at 6 and 12 weeks. The result of present investigation also supports the findings of Baigent et al., ${ }^{15}$, reporting that atorvastatin has low rates of myalgia at all doses $(10-80 \mathrm{mg} /$ day $)$. The patient characteristics that increase the risk of myopathy include low body mass index, female gender, hypothyroidism, hepatic or renal dysfunction, age $>80$ years, polypharmacy and the use of medications that interact with statins ${ }^{16}$. No cases of new onset of diabetes mellitus was detected during the 12 weeks study period. Analysing the miscellaneous adverse effects spontaneously reported by the subjects, one subject in each group had myalgia (without CK elevation). There was a single case of mild polyarthralgia in $10 \mathrm{mg}$ group and one case of insomnia in $40 \mathrm{mg}$ group. Our results are consistent with DALI study ${ }^{17}$ which showed that the number of adverse effects were same in low and high doses of atorvastatin. Another study by Barakat et al., ${ }^{18}$ concludes that different dosages of statins did not significantly affect the serum creatinine and glomerular filtration rate after 2 years. Results of the present investigation also correlate with the previous study of $\mathrm{Ye}$ et al. ${ }^{19}$ reporting that the overall incidence of treatment-associated adverse events observed with atorvastatin did not increase in the $10-80 \mathrm{mg}$ dose range. Therefore according to this observational study, there is no significant difference in adverse outcome as far as low dose or high dose of atorvastatin usage is concerned in post coronary or cerebrovascular event therapy. And in addition the drug appeared to be safe and did not produce any major side effects in the study population during this trial. 


\section{REFERENCES}

1. Aqeel MT, Ur-Rahman N, Khan AU, Ashraf Z, Latif M, Rafique H, Rasheed U. Anti hyperlipidemic studies of newly synthesized phenolic derivatives: in silico and in vivo approaches. Drug Des Devel Ther. 2018 Aug 9; 12:2443-2453.

2. Kumar P, Kumar A, Srivastava MK, Misra S, Pandit AK, Prasad K. Association of transforming growth factor beta-1-509C/T Gene polymorphism with ischemic stroke: A meta-analysis. Basic Clin Neurosci. 2016 Apr; 7(2):916.

3. Pooja BA, Bhatted S, Chaturvedi N, Deekshit S, Bhojani MK. Role of Atorvastatin in dyslipidemia: A clinical study. Indian Journal of Clinical Practice, 2013 Dec 24 (7): 620-22.

4. Li M, Liu F, Sang M, Sun X, Li L, Wang X. Effects of atorvastatin on p38phosphorylation and cardiac remodeling after myocardial infarction in rats. ExpTher Med. 2018 Aug; 16(2):751-757.

5. Katzung BG, Masters SB, Trevor AJ. Basic and clinical pharmacology,

New York City: McGraw-Hill Medical; 2009.

6. Leite-Moreira AF, Castro-Chaves P. Heart failure: statins for all? Heart. 2006Nov; 92(11):1537-8.

7. Thompson PD, Moyna NM, White CM, Weber KM, Giri $\mathrm{S}$, Waters DD. The effects ofhydroxy-methyl-glutaryl coenzyme A reductase inhibitors on platelet thrombus formation. Atherosclerosis. 2002 Apr; 161(2):301-6.

8. Dangas G, Badimon JJ, Smith DA, Unger AH, Levine D, Shao JH, Meraj P, Fier C, Fallon JT, Ambrose JA. Pravastatin therapy in hyperlipidemia: effects on thrombus formation and the systemic hemostatic profile. J Am Coll Cardiol. 1999Apr; 33(5):1294-304.

9. Staffa JA, Chang J, Green L. Cerivastatin and reports of fatal rhabdomyolysis.N Engl J Med. 2002 Feb 14; 346(7):539-40.

10. Dujovne CA. Side effects of statins: hepatitis versus "transaminitis"-myositis versus “CPKitis". Am J Cardiol. 2002; 89 (12): 1411-3
11. Bays H. Statin safety: an overview and assessment of the data-2005. Am J Cardiol.2006; 97(8A): 6C-26C

12. Yoo J, Lee S, Kim K, Yoo S, Sung E, Yim J. Relationship between insulin resistance and serum alanine aminotransferase as a surrogate of NAFLD (nonalcoholic fatty liver disease) in obese Korean children. Diabetes Res Clin Pract. 2008; 81(3): 321-6

13. Kundee SS, Lazenby AJ, Clements RH, Abrams GA. Spectrum of NAFLD diagnostic implications of the proposed new normal range for serum ALT in obese women. Hepatology. 2005; 42(3): 650-6

14. Thompson PD, Clarkson PM, Rosenson RS, National Lipid Association Statin Safety Task Force Muscle Safety Expert Panel. An assessment of statin safety by muscle experts. Am J Cardiol. 2006;97(8A): 69C-76C

15. Baigent C, Keech A, Kearney PM, et al. Efficacy and safety of cholesterol-lowering treatment: prospective meta-analysis of data from 90,056 participants in 14 randomised trials of statins. Lancet. 2005;366(9493): $1267-78$

16. Thompson PD, Clarkson P, Karas RH. Statin-associated myopathy. JAMA. 2003;289(13): 1681-90

17. Diabetes Atorvastatin Lipid Intervention (DALI) Study Group. The effect of aggressive versus standard lipid lowering by atorvastatin on diabetic dyslipidemia: the DALI study; a double blind, randomized, placebocontrolled trial in patients with type 2 diabetes and diabetic dyslipidemia. Diabetes care. 2001; 24(8): 133541

18. Barakat L, Jayyousi A, Bener A, Zuby B, Zirie M. Comparison of efficacy and safety of Rosuvastatin, Atorvastatin and Pravastatin among dyslipidemic diabetic patients. ISRN Pharmacol. 2013; 2013: 146579

19. Ye YC, Zhao XL, Zhang SY. Use of atorvastatin in lipid disorders and cardiovascular disease in Chinese patients. Chin Med J (Engl). 2015; 128(2): 259-66.

Source of Support: None Declared Conflict of Interest: None Declared 